\title{
Nonstandard Work Schedules in Cross-National Perspective: \\ A Study of 29 European Countries, 2005-2015
}

\author{
Pablo Gracia, Trinity College Dublin (graciap@tcd.ie) ${ }^{+}$ \\ Wen Jui-Han, New York University (wjh3@nyu.edu)
}

Jianghong Li, Berlin Social Science Centre,WZB (jianghong.li@wzb.eu)

\begin{abstract}
Data from the 'European Working Conditions Survey' from 2005 to 2015 for 29 European countries show that the incidence of nonstandard work schedules (evenings, nights, weekends, rotating, shifts) differs remarkably across European regions with different public policies. Working nonstandard schedules differs by education, gender and parental status across Europe.
\end{abstract}

${ }^{+}$Corresponding author: School of Social Sciences and Philosophy, Department of Sociology, 3 College Green, Trinity College, Dublin 2, Ireland 


\section{Nonstandard Work Schedules: A Cross-National Approach}

Working the standard 9am-5pm is no longer the norm for many workers in the $24 / 7$ economy. Workers are increasingly required to be employed at unsociable hours, facing highly globalized and deregulated labor markets characterized by job volatility and unpredictability ${ }^{1}$. Nonstandard work schedules often go together with precarious jobs that put physical and psychological pressure on workers, especially among the most vulnerable groups in society ${ }^{2}$. In the current Covid-19 pandemic, which is affecting demographic groups differently depending on their flexible conditions ${ }^{3}$, understanding who works nonstandard work schedules becomes crucial.

This article examines recent trends in nonstandard work schedules, using data from 2005 to 2015 across five European regions, covering 29 countries. Following Harriet B. Presser's seminal study $^{3}$, we define nonstandard work schedules as paid work hours on the main job occurring outside the standard 9am-5pm daytime shift or during irregular and unpredictable hours (e.g., non-daytime work hours; rotative hours; being on calls). Nonstandard work schedules are associated with adverse physical and mental health outcomes for workers ${ }^{4}$ and can lead to high work-family and work-life conflicts $^{5,6}$. Studies reveal that less-skilled workers are more prone to work under unpredictable nonstandard work schedules, compared to high-skilled workers ${ }^{7}$. Nonstandard work schedules can harm women's labor market chances particularly: women often opt for leaving the labor market when facing unsociable schedules that make difficult to reconcile paid work and caring activities ${ }^{8,9}$. Studies have also found that nonstandard work schedules can harm parent-child relations which are critical for child well-being ${ }^{10,11}$.

A study by Presser and colleagues, using data from the 2005 Labor Survey for 12 Western European countries, found that nonday shifts are more prevalent in an English-speaking country (e.g., United Kingdom), compared to Scandinavian countries (e.g. Denmark) and Continental countries (e.g. Luxemburg) ${ }^{12}$. The same study found that a Scandinavian country (e.g., Finland) has smaller gender differences in nonstandard work schedules, compared to Continental countries (e.g. Austria) and English-speaking countries (e.g. United Kingdom), where men worked nonstandard schedules to 
a much higher extent than women ${ }^{13}$. Yet, this study, like other previous studies, did not include nonWestern European countries (e.g. Central-East Europe) and covered only the pre-2008 Recession period. Our study provides fresh data on this important topic.

We examine nonstandard work schedules using data from the European Working Conditions Survey including 29 European countries across three time points spanning a decade, including the pre-2008 recession (2005), the immediate recession period (2010), and a period of relative economic recovery $(2015)^{14}$. Drawing on previous welfare state literature, in Scandinavia -a region with strong labor market regulation and protection through active public policies and legislations (i.e., workfamily programs, minimum wages policies, restricted business hours)- workers would have quite favorable opportunities to avoid working nonstandard schedules, meaning that the prevalence of these work schedules would be low across demographic groups ${ }^{15}$. By contrast, in regions with limited labor market protection, such as countries in East-Central Europe, Southern Europe, and Anglo-Celtic countries with strong liberal market-oriented policies, employees might be more exposed to working nonstandard schedules ${ }^{16}$. We show how nonstandard work schedules differ across European regions by considering three key factors: (1) education, (2) gender and (3) parental status.

\section{Data}

Our data come from the European Working Conditions Survey (EWCS) for 29 European countries, using information collected for the three most recent available waves: 2005, 2010, 2015. The EWCS is administered by Eurofound ${ }^{17}$ with its survey partner Ipsos NV to randomly select and interview individuals from a statistical and cross-section sample of each country included in the EWCS. Depending on the country's population size and feasibility concerns, the sample ranged from 1,000 to 3,300 people per country. Table 1 provides details of the exact number of participants included in the study. The analytic sample for this study was nationally representative of each country. Face-to-face interviews were carried out in peoples' homes with questions regarding their working conditions and other demographic questions. All three waves $(2005,2010,2015)$ used in this study followed the same data collection procedure. 
Our samples included a total of 93,879 workers across these 29 countries. We analyze repeated measures across three cross-sectional waves, including Wave 1 in $2005(\mathrm{~N}=25,436)$, Wave 2 in $2010(\mathrm{~N}=34,688)$, and Wave 3 in $2015(\mathrm{~N}=33,755)$. The samples are representative of the working population aged 18-64 for each wave of the EWCS included in our data. Sample weights were used in the analyses to ensure the representative nature of all countries of study.

We categorize the 29 European countries along five regions that cluster with different public policy traditions: (1) Scandinavia (Denmark, Finland, Norway, and Sweden); (2) Continental Europe (Austria, Belgium, France, Germany, Luxemburg, and the Netherlands); (3) Anglo-Celtic (Ireland and UK); (4) Southern European (SE) (Cyprus, Greece, Italy, Malta, Portugal, and Spain), and; (5) Central-Eastern European (CEE) (Bulgaria, Croatia, Czech Republic, Estonia, Hungary, Latvia, Lithuania, Poland, Romania, Slovakia, and Slovenia). Table 1 presents the sample size across country and wave for all 29 countries included in the data.

[Table 1 around here]

Our outcome measure is nonstandard work schedules. This is a binary variable identifying employees who have (against not having) nonstandard work schedules, based on whether workers declared in the EWCS survey being employed under one or more of these options: (1) frequent nonday shifts (i.e., evenings, nights, split shifts); (2) frequent rotating hours or days, or; (3) weekend work during most weekends of the month (i.e., at least three times a month).

Our analyses show the percentage of workers with nonstandard schedules across the 29 countries included in our data. We particularly examine differences in nonstandard work schedules across the five European regions of study, including trends from 2005 to 2015 . Finally, we investigate the probabilities of working nonstandard work schedules across the five European regions of study, using multivariate logistic regressions adjusting for selected covariates (i.e., age, marital status, occupation, migrant status) across (1) education, (2) gender and (3) parental status.

\section{Nonstandard Work Schedules in 29 Countries}

Figure 1 shows the actual percentage of workers with nonstandard work schedules across 29 
European countries in the period 2005-2015. While more than 1 out of 3 workers (39\%) in our sample work nonstandard schedules, we observe notable cross-national differences in the incidence of working nonstandard schedules. The prevalence of nonstandard work schedules ranges from -at the bottom of the list- $20 \%$ in Denmark, $22 \%$ in Sweden and $25 \%$ in the Netherlands to -at the top of the list $-50 \%$ in Italy, $51 \%$ in Poland, $52 \%$ in Romania, $54 \%$ in Croatia, and 56\% in Greece. In nine countries, nonstandard work schedules range between $35 \%$ and $40 \%$ of prevalence, including five Central-East European countries (i.e., Estonia, Cyprus, Latvia, Lithuania, and Slovakia), two AngloCeltic countries (i.e., Ireland, UK), one Southern European country (i.e., Portugal), and one Continental European country (i.e., France).

[Figure 1 around here]

\section{Nonstandard Work Schedules in Five European Regions}

Table 2 shows the percentage of workers employed with nonstandard schedules across five European regions. We observe important regional differences in the incidence of nonstandard work schedules across regions. In Scandinavia, $27 \%$ of workers have nonstandard work schedules, followed by Continental European countries, with $34 \%$ of workers having nonstandard schedules, and by Anglo-Celtic countries, with 38\% of employees with nonstandard work schedules. Southern European countries have the largest percentage of workers with nonstandard schedules, accounting for $46 \%$ of employees, closely followed by the group of Central-East European countries, where $43 \%$ of employees have nonstandard work schedules.

[Table 2, around here]

\section{Nonstandard Work Schedules: Evolution from 2005 to 2015}

Figure 2 shows the probabilities of working nonstandard schedules at three time points (2005, 2010, 2015) across all five European regions. Analyses adjust for demographic and socioeconomic variables. We observe that, between 2005 (pre-recession) and 2010 (recession), the likelihood of working nonstandard schedules slightly decreased in Southern Europe (from 44\% to 43\%), CentralEast Europe (44\% to $40 \%$ ), and Scandinavia (from $30 \%$ to $27 \%$ ), while it remained stable in Anglo- 
Celtic countries (at 37\%) and Continental Europe (at 35\%). Between 2010 (recession) and 2015 (postrecession), the incidence of nonstandard work schedules returned to similar levels as in 2005 in Southern Europe (46\%) and Central-East Europe (43\%), but also in Scandinavia (32\%). In Continental Europe there was a slight decline (from 35\% in 2010 to $33 \%$ in 2015) in the probabilities of working nonstandard schedules. By contrast, the probabilities of nonstandard work schedules increased from 37\% in 2010 to $42 \%$ in 2015 in the Anglo-Celtic cluster, with English-speaking countries showing the sharp increase in nonstandard work schedules from all regions.

[Figure 2 around here]

Table 3 allows us to examine if the likelihood of working nonstandard schedules differs significantly across years within each of the five European regions of study, adjusting for demographic and socioeconomic variables. Except for Continental European countries, differences in the likelihood of working nonstandard schedules between years were statistically significant, and particularly so when comparing 2010 to $2015(p<0.001)$. In the cluster of Continental European countries, differences in the likelihood of working nonstandard schedules were not statistically significant when comparing 2005 to 2010 or when comparing 2010 to 2015.

[Table 3, around here]

\section{Educational Differences in Nonstandard Work Schedules}

Figure 3 shows the probabilities of working nonstandard work schedules (presented as percentages) between workers holding a college degree and workers with lower levels of education across the five European regions of the study. Analyses adjust for demographic and socioeconomic variables. We observe that college-educated workers are less likely to work nonstandard work schedules than their less-educated counterparts. Yet, these educational variations in nonstandard work schedules differ remarkably across European regions.

[Figure 3 around here]

Figure 3 shows that educational differences in nonstandard work schedules are smallest in Scandinavian countries, with a $24 \%$ incidence for the college educated and $31 \%$ for the less educated. 
We find larger educational differences in the probability of working nonstandard schedules in Continental Europe (27\% for the college educated; $38 \%$ for those with lower qualifications) and in Anglo-Celtic countries (31\% among the college educated; $42 \%$ for those without a college degree). In Southern Europe, we find much larger educational gaps in the probability of working nonstandard schedules: $33 \%$ for workers holding a college degree versus $49 \%$ for those with lower qualifications. Finally, the largest educational gap in the probabilities of nonstandard work schedules exists in Central-East European countries, with a $27 \%$ of probability of working nonstandard work schedules among college educated, against $49 \%$ for employees without a college degree. Educational differences in nonstandard work schedules are smallest in Scandinavia, a region with low levels of socioeconomic inequalities and high social benefits ${ }^{18}$. Educational gaps in nonstandard work schedules are at intermediate levels in both Continental European countries and Anglo-Celtic countries. In Southern Europe, and especially in Central-East Europe, we observe the highest levels of educational inequalities in nonstandard work schedules, where less-educated workers are particularly likely to work nonstandard schedules, and many of whom are employed under low-paid and precarious contracts ${ }^{19}$.

[Table 4, around here]

Table 4 examines whether differences in the probabilities of working nonstandard schedules by educational levels (college degree vs. below college degree) were significant within each of the five European regions of study, net of all other control variables. Although educational variations in the likelihood of working nonstandard schedules were statistically significant in all five region clusters, these variations were statistically stronger in Southern Europe, Continental Europe, and Central-East Europe $(\mathrm{p}<0.001)$, closely followed by English-speaking countries $(\mathrm{p}<0.01)$ and less so in Scandinavia $(\mathrm{p}<0.05)$.

\section{Gender Differences in Nonstandard Work Schedules}

Figure 4 shows the probabilities of working nonstandard work schedules (as percentages) among men and women across five European regions, adjusted by demographic and socioeconomic 
factors. These analyses show two clear findings. First, gender differences in working nonstandard schedules seem smaller than the abovementioned educational differences. Second, men are more likely than women to work nonstandard work schedules in all regions, except in Scandinavia, where women are slightly more likely than men to work nonstandard schedules.

[Figure 4 around here]

Figure 4 shows that the probability of working nonstandard schedules in Scandinavia is $29 \%$ among men and $31 \%$ among women. In Continental Europe, men are more likely than women to work nonstandard schedules (36\% among men; 32\% among women), with similar gender gaps in Southern Europe (42\% among women; 46\% among men) and in the Central-East European cluster (44\% among men; 41\% among women). The largest gender differences in the likelihood of working nonstandard schedules appear in Anglo-Celtic countries, with probabilities of 35\% among women, compared to probabilities of $43 \%$ among men. That is, Scandinavian countries are unique in that women are more likely than men to work nonstandard schedules, which might reflect similar levels of working flexibility across genders in Scandinavia ${ }^{20}$. In the other four European regions, men work nonstandard schedules more than women, with moderate gender gaps in Continental Europe, Southern Europe, and Central-East Europe. Anglo-Celtic countries have the largest gender differences in nonstandard work schedules, showing that men -who often work long hours across economic sectors in these English-speaking countries- are the most affected by having nonstandard work schedules, while women -many working part-time in these countries- are relatively more oriented towards flexible standard work schedules ${ }^{21}$.

[Table 5, around here]

Table 5 presents the likelihood of working nonstandard schedules by gender within each of the five European regions of study, net of all other demographic and socioeconomic variables. For Continental Europe, the Anglo-Celtic cluster, and Southern Europe, the observed higher probability of working nonstandard work schedules among men showed strong statistical associations $(p<$ 0.001). The higher tendency of women to work nonstandard work schedules in the Scandinavian 
cluster was also statistically significant $(p<0.01)$. In contrast, the gender difference in the likelihood of working nonstandard work schedules in Central-East Europe was not statistically significant.

\section{Nonstandard Work Schedules by Parental Status}

Table 6 shows the probabilities of working nonstandard schedules by gender and region across four groups by parental status: without children aged 0-17 (having no children or children aged 18 or older); with the youngest child aged 0-5; with the youngest child aged 6-11; with the youngest child aged 12-17 (reference group). Results are presented with odds ratios, where values above 1 indicate higher odds of working nonstandard schedules $(+)$ and values below 1 indicate lower odds for working nonstandard schedules (-), compared to the odds of working nonstandard work schedules for the reference group (workers with the youngest child aged 12-17). These models adjust for demographic and socioeconomic factors. For brevity, we only highlight results that are statistically significant at the $95 \%$ confidence level.

Table 6 shows generally insignificant differences in nonstandard work schedules by men's parental status. The only significant result for men is found in the Southern European cluster, where men without children have lower odds of working nonstandard schedules $(0.883)$, compared to the odds for those with the youngest child at home aged 12-17. For women, we find more differences by parental status in the probabilities of working nonstandard work schedules, even if these differences are only statistically significant in Scandinavian and Continental European countries. Mothers in Scandinavia with the youngest child aged 0-5 (0.780) and with the youngest child aged 6-11 (0.737) have significantly lower odds of working nonstandard schedules than Scandinavian mothers with the youngest child aged 12-17. Also, in the Continental European cluster, women without dependent children at home aged 0-17 show significantly higher odds of working nonstandard schedules (1.107), compared to the odds for mothers with the youngest child aged 12-17.

[Table 6 around here]

To summarize, men's probabilities of working nonstandard schedules hardly differ by parental status, except in Southern Europe, where men have particularly low probabilities of working 
nonstandard schedules. By contrast, women without children aged 0-17 at home tend to have higher chances of working nonstandard schedules than women with non-adult children at home, with statistically significant differences in Continental Europe. Scandinavian countries are an exception regarding the role of children's age in mothers' likelihood of working nonstandard schedules, where the probabilities of working nonstandard are clearly lower among mothers with children of preschool age and primary education than among mothers with older children. These findings seem to suggest that highly extended family-friendly policies of Scandinavia allow women with small children to avoid the option of working nonstandard schedules.

\section{Summary of Results}

- The presence of nonstandard work schedules differs remarkably across European regions. Nonstandard work schedules are more prevalent in Southern European and Central-Eastern European countries, followed by Anglo-Celtic countries, and less so in Continental countries. Scandinavia shows the lowest presence of nonstandard work schedules.

- In most regions (Central-East Europe, South Europe, and Scandinavia), there was a decrease in the prevalence of nonstandard work schedules from 2005 to 2010 but these regions returned to pre-recession levels in 2015. In Continental Europe, there was stability in the prevalence of nonstandard work schedules from 2005 to 2010, followed by a marginal decline in 2015 . Finally, results show a persistence in nonstandard work schedules from 2005 to 2010 in Anglo-Celtic countries, but with a remarkable increase in the percentage of workers with nonstandard schedules in 2015.

- Workers holding a college degree are less likely to work nonstandard schedules, compared to workers without a college degree. Yet, these educational gaps differ across European regions, being low in Scandinavia, high in Southern Europe and Central-East Europe, and in between these two poles in Continental and Anglo-Celtic countries.

- Men are more likely than women to work nonstandard schedules in Continental Europe, Central-East Europe, and Southern Europe, and especially so in Anglo-Celtic countries. Yet, 
in Scandinavia, women are slightly more likely than men to work nonstandard schedules.

- Only among Scandinavian mothers, the age of the youngest child at home plays a role in whether or not a mother works nonstandard schedules, where only women with younger children have low chances of working nonstandard schedules.

\section{Conclusion}

This article presents a systematic analysis of how nonstandard work schedules differ across five European regions with different public policy contexts, using high-quality data from European Working Conditions Survey (EWCS) from 2005 to 2015. Results reveal that regions with a tradition of higher social protection, such as Scandinavia, and to a lesser extent Continental Europe, have a lower incidence of nonstandard work schedules. By contrast, Southern European and East-Central European countries show particularly high levels of nonstandard work schedules, a type of work schedule that is associated with poorer health, lower work autonomy and higher work-family conflict levels. The 2008 recession reduced the incidence of nonstandard work schedules in Europe, but after the recovery there was again a return to pre-recession levels, with an important increase in the incidence of nonstandard work schedules in English-speaking countries in 2015.

Education and gender play an important role in shaping nonstandard work schedules. We find clear differences by education and -to a lesser extent- gender in the incidence of working nonstandard work schedules. The magnitude and direction of these variations is dissimilar across European regions with different policy and labor market traditions. Also, we observe some variations in the incidence of working nonstandard schedules by parental status, with relevant differences across Europe. Overall, the findings of this study contribute to current debates about working conditions across regions with different policy, social and economic contexts by providing an exhaustive examination of nonstandard work schedules, using detailed data from 29 European countries. 


\section{Footnotes}

${ }^{1}$ For a discussion of current debates on precarious and nonstandard employment in the US and other industrialized countries, see: Kalleberg, A. L. (2013).

${ }^{2}$ See the study of Matthew Dey, Harley Frazis, Mark A. Loewenstein, and Hugette Sun (2020). The authors analyze current patterns of telework in the Covid-19 pandemic in the US, showing important demographic differences in such patterns. While the authors do not examine differences in nonstandard work schedules, the literature shows that nonstandard work schedules (i.e., rotating shifts, irregular hours) are subject to higher levels of unpredictability and insecurity, which are jobs that are particularly endangered during structural economic crisis; see Presser, H. B. (2003).

${ }^{3}$ see Presser, H. B. (2003).

${ }^{4}$ for a complete review of this literature, see Moreno CR, Marqueze EC, Sargent C, et al. (2019).

${ }^{5}$ see Kalil A, Ziol-Guest KM and Levin Epstein J (2010).

${ }^{6}$ see Maume DJ and Sebastian RA (2012).

${ }^{7}$ see the study of Presser, H. B. (2003), which reports such differences by education and social class in nonstandard work schedules in the US.

${ }^{8}$ see Gracia, P., \& Kalmijn, M. (2016).

${ }^{9}$ see Craig, L., \& Powell, A. (2011).

${ }^{10}$ see Han, W. J. (2008).

${ }^{11}$ see Li, J., Johnson, S. E., Han, W. J., Andrews, S., Kendall, G., Strazdins, L., \& Dockery, A. (2014).

${ }^{12}$ see Presser, H. B., Gornick, J. C., \& Parashar, B. (2008).

${ }^{13}$ see Presser, H. B., Gornick, J. C., \& Parashar, B. (2008).

${ }^{14}$ a study by Roxanna Edwards and Sean M. Smith (2020) shows trends in unemployment in the US by showing how 2009/10 had extremely high levels of unemployment, compared to 2005 and 2015. While EU countries were hit by the 2008 economic recession in different ways, data show an important economic recovery in consumption and economic activity in 2015, compared to 2010, while unemployment was also clearly higher in 2010 than in 2005 (OECD 2015).

${ }^{15}$ the study of Esping-Andersen (1999) incorporates a discussion of European welfare states and social policy across different regions (defined as welfare regimes) by considering the linkages between states, families and markets in the provision of welfare. This typology has been extensively used to investigate labor market policies in Europe, which in many respects can be clustered across different European regions.

${ }^{16}$ for a revision of the literature on welfare regimes and social policies in industrialized countries, see the study of Ferragina, E., \& Seeleib-Kaiser, M. (2011).

${ }^{17}$ see European Working Conditions Survey 2005-2015 (2015).

${ }^{18}$ a recent OECD (2019) shows that in terms of relative poverty, social protection and income inequalities, Scandinavian countries are among the most egalitarian across OECD countries. These low educational inequalities in the incidence of working nonstandard schedules in Scandinavian countries are likely to be, at least partly, explained by the opportunities of less-educated workers to avoid working outside regular hours, compared to countries with lower salaries and lower job protection among less-skilled workers.

${ }^{19}$ recent evidence shows that Central-East European countries experienced the highest levels of precarious conditions in the European Union since the 2008 Great Recession, while the risks of having precarious jobs particularly pronounced among less-skilled workers; see for example Matilla-Santander, N., Lidón-Moyano, C., González-Marrón, A., Bunch, K., Martín-Sánchez, J. C., \& Martínez-Sánchez, J. M. (2019). Other studies reveal the nature of temporary and fixed-term jobs in Southern European countries, especially among less-skilled workers, with workers facing high levels of job insecurity and risks of experiencing poverty; see for example, Kretsos, L., \& Livanos, I. (2016).

${ }^{20}$ for a review of different trends in family-friendly policies and gender equality policies in Europe, a complete review is that of Lewis, J. (2009).

${ }^{21}$ see Lewis, J. (2009), where the author discussed into detail the role of female part-time employment in Anglo-Saxon countries, paying particular attention to case of the United Kingdom. 


\section{References}

Craig, L., \& Powell, A. (2011). Non-standard work schedules, work-family balance and the gendered division of childcare. Work, Employment and Society, 25(2), 274-291.

Dey, M. Frazis, H., Loewenstein, M., \& Sun, H. (2020). Ability to work from home: evidence from two surveys and implications for the labor market in the COVID-19 pandemic. Monthly Labor Review, U.S. Bureau of Labor Statistics (June 2020); https://doi.org/10.21916/mlr.2020.14.

Edwards, R., \& Smith, S. M. (2020). Job market remains tight in 2019, as the unemployment rate falls to its lowest level since 1969. Monthly Labor Review, 143, 1. https://doi.org/10.21916/mlr.2020.8.

Esping-Andersen, G. (1999). Social foundations of postindustrial economies. OUP: Oxford.

European Working Conditions Survey, 2005-2015: https://www.eurofound.europa.eu/surveys/europeanworking-conditions-surveys-ewcs

Ferragina, E., \& Seeleib-Kaiser, M. (2011). Thematic Review: Welfare regime debate: past, present, futures?. Policy \& Politics, 39(4), 583-611).

Gracia, P., \& Kalmijn, M. (2016). Parents' family time and work schedules: The split-shift schedule in Spain. Journal of Marriage and Family, 78(2), 401-415.

Han, W. J. (2008). Shift work and child behavioral outcomes. Work, Employment and Society, 22(1), 67-87.

Kalil A, Ziol-Guest KM \& Levin Epstein J (2010) Nonstandard work and marital instability: Evidence from the National Longitudinal Survey of Youth. Journal of Marriage and Family 72(5): 1289-1300.

Kalleberg, A. L. (2013). Globalization and precarious work. American Sociological Review, 42(5), 700-706. doi:10.1177/0094306113499536.

Kretsos, L., \& Livanos, I. (2016). The extent and determinants of precarious employment in Europe. International journal of manpower

Lewis, J. (2009). Work-family balance, gender and policy. Edward Elgar Publishing

Li, J., Johnson, S. E., Han, W. J., Andrews, S., Kendall, G., Strazdins, L., \& Dockery, A. (2014). Parents' nonstandard work schedules and child well-being: A critical review of the literature. The journal of primary prevention, 35(1), 53-73.

Matilla-Santander, N., Lidón-Moyano, C., González-Marrón, A., Bunch, K., Martín-Sánchez, J. C., \& Martínez-Sánchez, J. M. (2019). Measuring precarious employment in Europe 8 years into the global crisis. Journal of Public Health, 41(2), 259-267)

Maume DJ and Sebastian RA (2012) Gender, nonstandard work schedules, and marital quality. Journal of Family and Economic Issues 33(4): 477-490.

Moreno CR, Marqueze EC, Sargent C, et al. (2019) Working time society consensus statements: Evidencebased effects of shift work on physical and mental health. Industrial health 57(2): 139-157.

OECD (2019). "Society at a Glance: 2019”. Paris: OECD Social Indicators.

OECD (2015). Employment Outlook, Paris: OECD.

Presser, H. B. (2003). Working in a 24/7 economy: Challenges for American families. New York: Russell Sage Foundation

Presser, H. B., Gornick, J. C., \& Parashar, B. (2008). Gender and nonstandard work hours in 12 European countries. Monthly Labor Review, February, 83-103. 
Table 1. Sample Size and Percentage by Country and Year

\begin{tabular}{lcccccc}
\hline & \multicolumn{2}{c}{2005} & \multicolumn{2}{c}{2010} & \multicolumn{2}{c}{2015} \\
\hline & $\mathrm{N}$ & $\%$ & $\mathrm{~N}$ & $\%$ & $\mathrm{~N}$ & $\%$ \\
\hline Austria (AU) & 920 & 3.62 & 920 & 2.65 & 961 & 2.85 \\
Belgium (BE) & 945 & 3.72 & 3706 & 10.68 & 2408 & 7.13 \\
Bulgaria (BU) & 1055 & 4.15 & 924 & 2.66 & 988 & 2.93 \\
Croatia (CR) & 929 & 3.65 & 861 & 2.48 & 773 & 2.29 \\
Cyprus (CY & 556 & 2.19 & 953 & 2.75 & 963 & 2.85 \\
Czech Republic (CZ) & 889 & 3.50 & 909 & 2.62 & 904 & 2.68 \\
Denmark (DK) & 962 & 3.78 & 1029 & 2.97 & 923 & 2.73 \\
Estonia (ES) & 537 & 2.11 & 885 & 2.55 & 878 & 2.60 \\
Finland (FI) & 995 & 3.91 & 983 & 2.83 & 945 & 2.80 \\
France (FR) & 942 & 3.70 & 2876 & 8.29 & 1467 & 4.35 \\
Germany (GE) & 973 & 3.83 & 2043 & 5.89 & 1959 & 5.80 \\
Greece (GR) & 921 & 3.62 & 985 & 2.84 & 963 & 2.85 \\
Hungary (HU) & 948 & 3.73 & 964 & 2.78 & 913 & 2.70 \\
Ireland (IRV & 928 & 3.65 & 946 & 2.73 & 972 & 2.88 \\
Italy (IT) & 900 & 3.54 & 1344 & 3.87 & 1223 & 3.62 \\
Latvia (LA) & 904 & 3.55 & 935 & 2.70 & 835 & 2.47 \\
Lithuania (LI) & 831 & 3.27 & 883 & 2.55 & 927 & 2.75 \\
Luxemburg (LU) & 543 & 2.13 & 910 & 2.62 & 961 & 2.85 \\
Malta (MA) & 553 & 2.17 & 947 & 2.73 & 957 & 2.84 \\
Netherlands (NL) & 997 & 3.92 & 975 & 2.81 & 963 & 2.85 \\
Norway (NO) & 921 & 3.62 & 1012 & 2.92 & 959 & 2.84 \\
Poland (PL) & 940 & 3.70 & 1308 & 3.77 & 993 & 2.94 \\
Portugal (PO) & 939 & 3.69 & 912 & 2.63 & 869 & 2.57 \\
Romania (RO) & 890 & 3.50 & 901 & 2.60 & 935 & 2.77 \\
Slovakia (SK) & 985 & 3.87 & 946 & 2.73 & 913 & 2.70 \\
Slovenia (SL) & 584 & 2.30 & 1352 & 3.90 & 1523 & 4.51 \\
Spain (SP) & 955 & 3.75 & 990 & 2.85 & 3220 & 9.54 \\
Sweden (SE) & 1020 & 4.01 & 855 & 2.46 & 953 & 2.82 \\
United Kingdom (UK) & 974 & 3.83 & 1434 & 4.13 & 1507 & 4.46 \\
\hline Total & 33755 & $100 \%$ & 34688 & $100 \%$ & 33755 & $100 \%$ \\
\hline & & & & & &
\end{tabular}

Table 2. Percentage of Employees with Nonstandard Work Schedules across Five European Regions

\begin{tabular}{lccccc}
\hline & Scandinavian & Continental & Anglo-Celtic & Southern Europe & Central-East Europe \\
\hline Percentage & $27 \%$ & $34 \%$ & $38 \%$ & $46 \%$ & $43 \%$ \\
Observations & 11,557 & 25,469 & 6,761 & 19,150 & 30,942 \\
\hline
\end{tabular}

Note: Employees aged 18-64 for a pooled sample with Wave 1 (2005), Wave $2(2010)$, and Wave $3(2015)(\mathrm{N}=93,879)$. 
Table 3. Odds Ratios. Nonstandard Work Schedules by Year in Five European Regions

\begin{tabular}{|c|c|c|c|c|c|}
\hline & Scandinavia & Continental & Anglo-Celtic & South Europe & Central-East \\
\hline 2005 & Ref. & Ref. & Ref. & Ref. & Ref. \\
\hline 2010 & $\begin{array}{c}0.899^{*}(-) \\
(0.05)\end{array}$ & $\begin{array}{c}1.030(+) \\
(0.04)\end{array}$ & $\begin{array}{c}0.981(-)^{\mathrm{xxx}} \\
\quad(0.07)\end{array}$ & $\begin{array}{c}0.951(-)^{\mathrm{xxx}} \\
(0.04)\end{array}$ & $\begin{array}{c}0.919^{* *}(-) \\
(0.03)\end{array}$ \\
\hline 2015 & $\begin{array}{c}1.137^{*}(+) \\
(0.06)\end{array}$ & $\begin{array}{c}0.992(-) \\
(0.04)\end{array}$ & $\begin{array}{c}1.222^{* * *}(+) \\
(0.08)\end{array}$ & $\begin{array}{c}1.137^{* * *}(+) \\
(0.04)\end{array}$ & $\begin{array}{c}1.081^{* *}(+) \\
(0.03)\end{array}$ \\
\hline $\mathrm{N}$ & 11557 & 25469 & 6761 & 19150 & 30942 \\
\hline
\end{tabular}

Note: Numbers represent odds ratios with robust standard errors in parentheses. Five separate logistic models were conducted measuring the probabilities of working nonstandard schedules as odds ratios. All models control for age, gender, education, occupational sector, family income, migrant status, parental status, and marital status. Odds ratios are interpreted as positive when the value is above 1 and negative when the value is below 1 .

${ }^{*} p<0.05,{ }^{* *} p<0.01$.

${ }^{\mathrm{xxx}}$ statistical differences between 2010 and 2015 at $p<0.001$ (statistical differences between 2010 and 2015 are insignificant for the Continental group)

Table 4. Odds Ratios. Nonstandard Work Schedules by Education in Five European Regions

\begin{tabular}{|c|c|c|c|c|c|}
\hline & Scandinavia & Continental & Anglo-Celtic & South Europe & Central-East \\
\hline College Degree (ref: no College) & $\begin{array}{c}\mathbf{0 . 8 8 9}^{*}(-) \\
(0.05)\end{array}$ & $\begin{array}{c}0.680^{* * * *}(-) \\
(0.02)\end{array}$ & $\begin{array}{c}0.827^{* *}(-) \\
(0.05)\end{array}$ & $\begin{array}{c}0.585^{* * *}(-) \\
(0.02)\end{array}$ & $\begin{array}{c}0.529^{* * * *}(-) \\
(0.02)\end{array}$ \\
\hline $\mathrm{N}$ & 11557 & 25469 & 6761 & 19150 & 30942 \\
\hline
\end{tabular}

Note: Numbers represent odds ratios with robust standard errors in parentheses. Five separate logistic models were conducted measuring the probabilities of working nonstandard schedules as odds ratios. All models control for age, gender, year, occupational sector, family income, migrant status, parental status, and marital status. Odds ratios are interpreted as positive when the value is above 1 and negative when the value is below 1 .

${ }^{*} p<0.05,{ }^{* *} p<0.01,{ }^{* * *} p<0.001$.

Table 5. Odds Ratios. Nonstandard Work Schedules by Gender in Five European Regions

\begin{tabular}{|c|c|c|c|c|c|}
\hline & Scandinavia & Continental & Anglo-Celtic & South Europe & Central-East \\
\hline Female (ref: Male) & $\begin{array}{c}1.117^{* *}(+) \\
(0.05)\end{array}$ & $\begin{array}{c}0.887^{* * * *}(-) \\
(0.02)\end{array}$ & $\begin{array}{c}0.760^{* * * *}(-) \\
(0.04)\end{array}$ & $\begin{array}{c}0.890^{* * * *}(-) \\
(0.03)\end{array}$ & $\begin{array}{c}.984(-) \\
(0.02)\end{array}$ \\
\hline $\mathrm{N}$ & 11557 & 25469 & 6761 & 19150 & 30942 \\
\hline
\end{tabular}

Note: Numbers represent odds ratios with robust standard errors in parentheses. Five separate logistic models were conducted measuring the probabilities of working nonstandard schedules as odds ratios. All models control for age, education, year, occupational sector, family income, migrant status, parental status, and marital status. Odds ratios are interpreted as positive when the value is above 1 and negative when the value is below 1 .

${ }^{*} p<0.05,{ }^{* *} p<0.01,{ }^{* * *} p<0.001$. 
Table 6. Odds Ratios. Nonstandard Work Schedules by Children's Presence and Age in Five European Regions

\begin{tabular}{|c|c|c|c|c|c|}
\hline & Scandinavia & Continental & Anglo-Celtic & South Europe & Central-East \\
\hline \multicolumn{6}{|l|}{ Men } \\
\hline Youngest Child Aged 12-17 & Ref. & Ref. & Ref. & Ref. & Ref. \\
\hline No Children Aged 0-17 & $\begin{array}{c}0.904(-) \\
(0.07)\end{array}$ & $\begin{array}{c}1.044(+) \\
(0.06)\end{array}$ & $\begin{array}{c}0.925(-) \\
(0.10)\end{array}$ & $\begin{array}{c}0.883^{*}(-) \\
(0.05)\end{array}$ & $\begin{array}{c}0.928(-) \\
(0.05)\end{array}$ \\
\hline Youngest Child Aged 0-5 & $\begin{array}{c}0.806(-) \\
(0.10)\end{array}$ & $\begin{array}{c}1.005(+) \\
(0.08)\end{array}$ & $\begin{array}{c}1.081(+) \\
(0.16)\end{array}$ & $\begin{array}{c}0.953(-) \\
(0.08)\end{array}$ & $\begin{array}{c}1.022(+) \\
(0.07)\end{array}$ \\
\hline Youngest Child Aged 6-11 & $\begin{array}{c}0.954(-) \\
(0.11)\end{array}$ & $\begin{array}{c}0.961(-) \\
(0.07)\end{array}$ & $\begin{array}{c}1.101(+) \\
(0.15)\end{array}$ & $\begin{array}{c}0.884(-) \\
(0.07)\end{array}$ & $\begin{array}{c}0.957(-) \\
(0.07)\end{array}$ \\
\hline $\mathrm{N}$ & 5505 & 12651 & 3432 & 10000 & 13802 \\
\hline \multicolumn{6}{|l|}{ Women } \\
\hline Youngest Child Aged 12-17 & Ref. & Ref. & Ref. & Ref. & Ref. \\
\hline No Children Aged 0-17 & $\begin{array}{c}0.952(-) \\
(0.07)\end{array}$ & $\begin{array}{c}\text { 1.107* }^{*}(+) \\
(0.06)\end{array}$ & $\begin{array}{c}1.132(+) \\
(0.11)\end{array}$ & $\begin{array}{c}1.087(-) \\
(0.06)\end{array}$ & $\begin{array}{c}0.927(-) \\
(0.04)\end{array}$ \\
\hline Youngest Child Aged 0-5 & $\begin{array}{c}0.780^{*}(-) \\
(0.10)\end{array}$ & $\begin{array}{c}0.920(-) \\
(0.07)\end{array}$ & $\begin{array}{c}1.019(+) \\
(0.15)\end{array}$ & $\begin{array}{c}0.850(-) \\
(0.08)\end{array}$ & $\begin{array}{c}0.982(-) \\
(0.07)\end{array}$ \\
\hline Youngest Child Aged 6-11 & $\begin{array}{c}0.737^{* *}(-) \\
(\mathbf{0 . 0 8 )}\end{array}$ & $\begin{array}{c}0.933(-) \\
(0.06)\end{array}$ & $\begin{array}{c}0.898(-) \\
(0.12)\end{array}$ & $\begin{array}{c}0.894(-) \\
(0.07)\end{array}$ & $\begin{array}{c}0.925(-) \\
(0.05)\end{array}$ \\
\hline $\mathrm{N}$ & 6052 & 12818 & 3329 & 9150 & 17140 \\
\hline
\end{tabular}

Note: Numbers represent odds ratios with robust standard errors in parentheses. Five separate logistic models were conducted measuring the probabilities of working nonstandard schedules as odds ratios. All models control for age, year, gender, education, occupational sector, family income, migrant status, and marital status. Odds ratios are interpreted as positive when the value is above 1 and negative when the value is below 1 .

${ }^{*} p<0.05,{ }^{* *} p<0.01,{ }^{* * *} p<0.001$. 
Figure 1. Share of Nonstandard Work Schedules in 29 European Countries

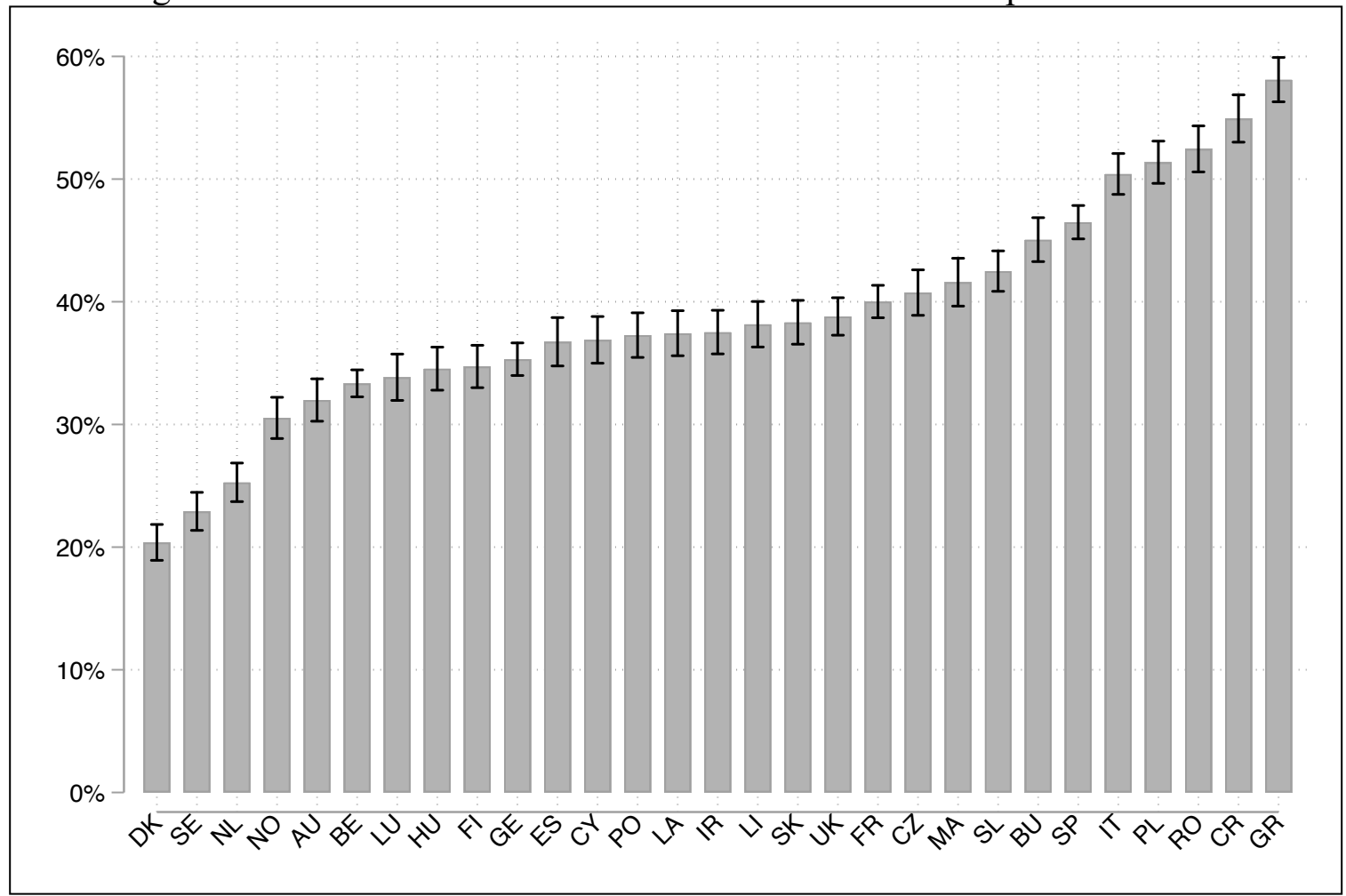

Note: Workers aged 18-64 with nonstandard work schedules in 29 countries for a pooled sample of Wave 1 (2005), Wave 2 (2010), and Wave 3 (2015) of the study ( $\mathrm{N}=93,879)$. CIs at the $95 \%$ are included, without controls. 
Figure 2. Probabilities (as \%) of Working Nonstandard Schedules by Regions and Year

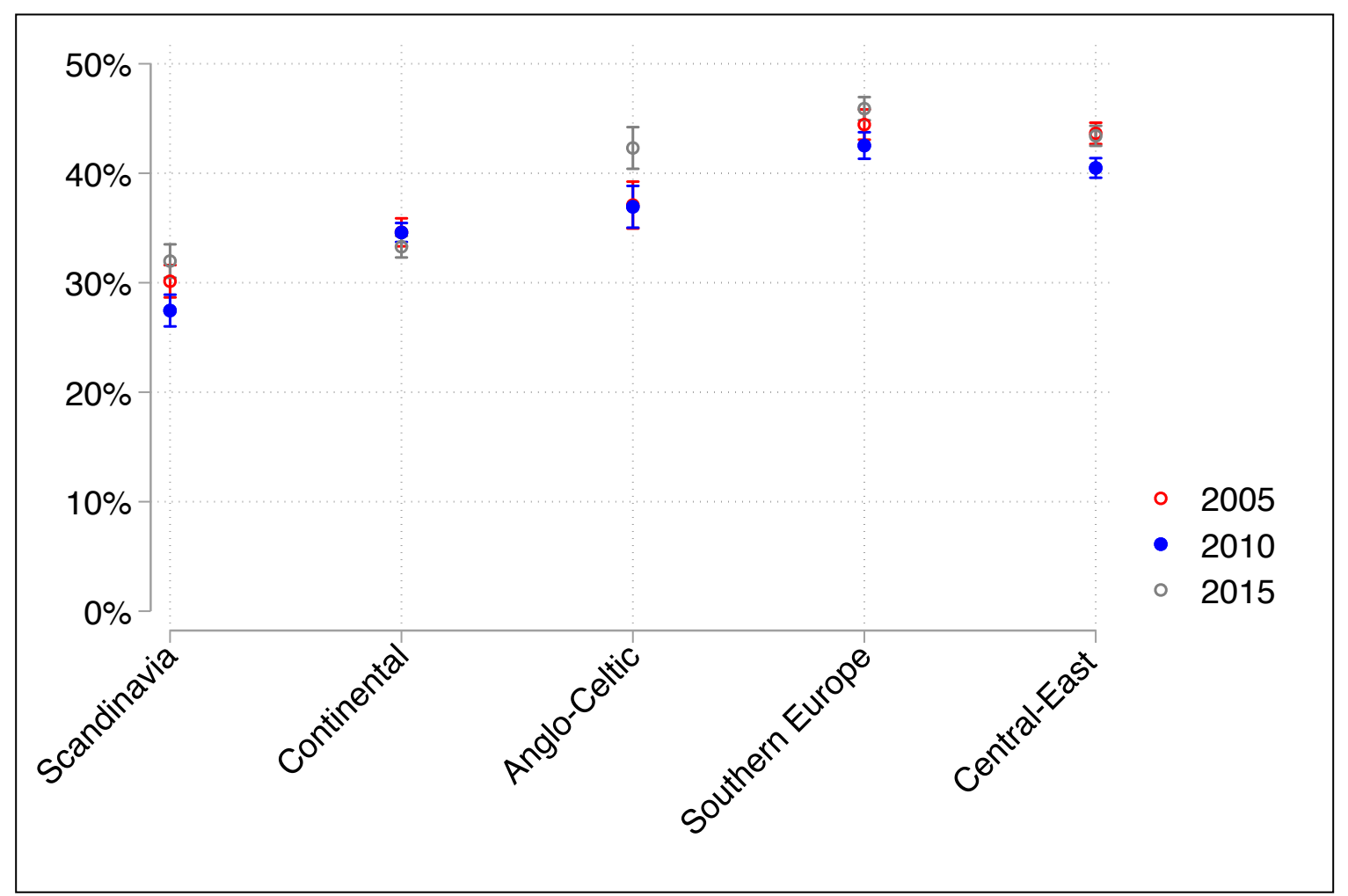

Note: Employees aged 18-64 for a pooled sample with Wave 1 (2005), Wave 2 (2010), and Wave 3 (2015) $(\mathrm{N}=93,879)$. The predicted probabilities (converted from a 0 to 1 scale to a 0 to 100 scale, to ease its interpretation) are based on logistic regression models with interactions with the five regions of study and adjusting for age, education, gender, education, occupational sector, family income, migrant status, parenthood status, and marital status. 
Figure 3. Probabilities (as \%) of Working Nonstandard Schedules by Regions and Education

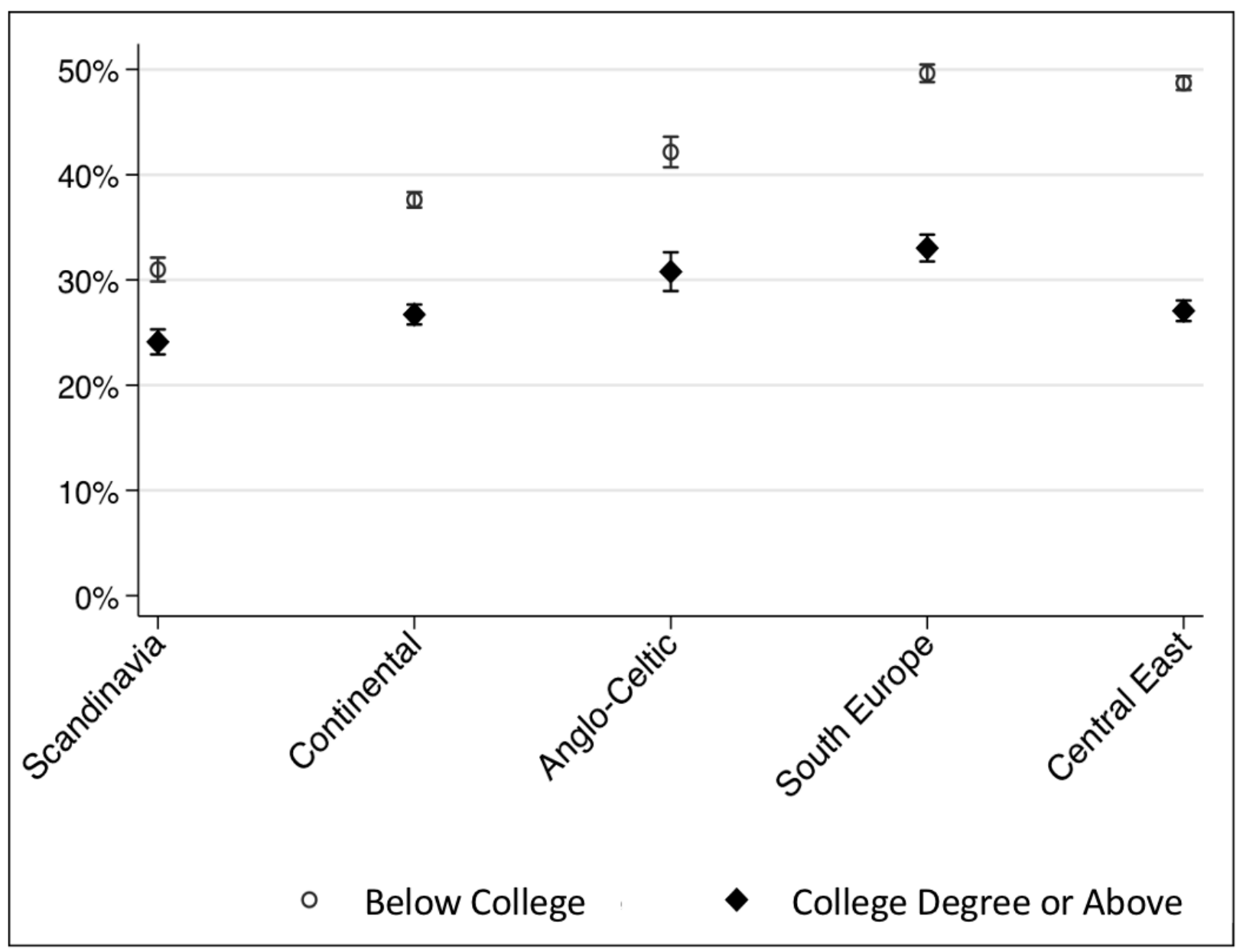

Note: Employees aged 18-64 for a pooled sample with Wave 1 (2005), Wave 2 (2010), and Wave $3(2015)(\mathrm{N}=93,879)$. The predicted probabilities (converted from a 0 to 1 scale to a 0 to 100 scale, to ease its interpretation) are based on logistic regression models with interactions with the five regions of study, adjusting for age, year, gender, occupational sector, family income, migrant status, parenthood status, and marital status. 
Figure 4. Probabilities (as \%) of Working Nonstandard Schedules by Regions and Gender

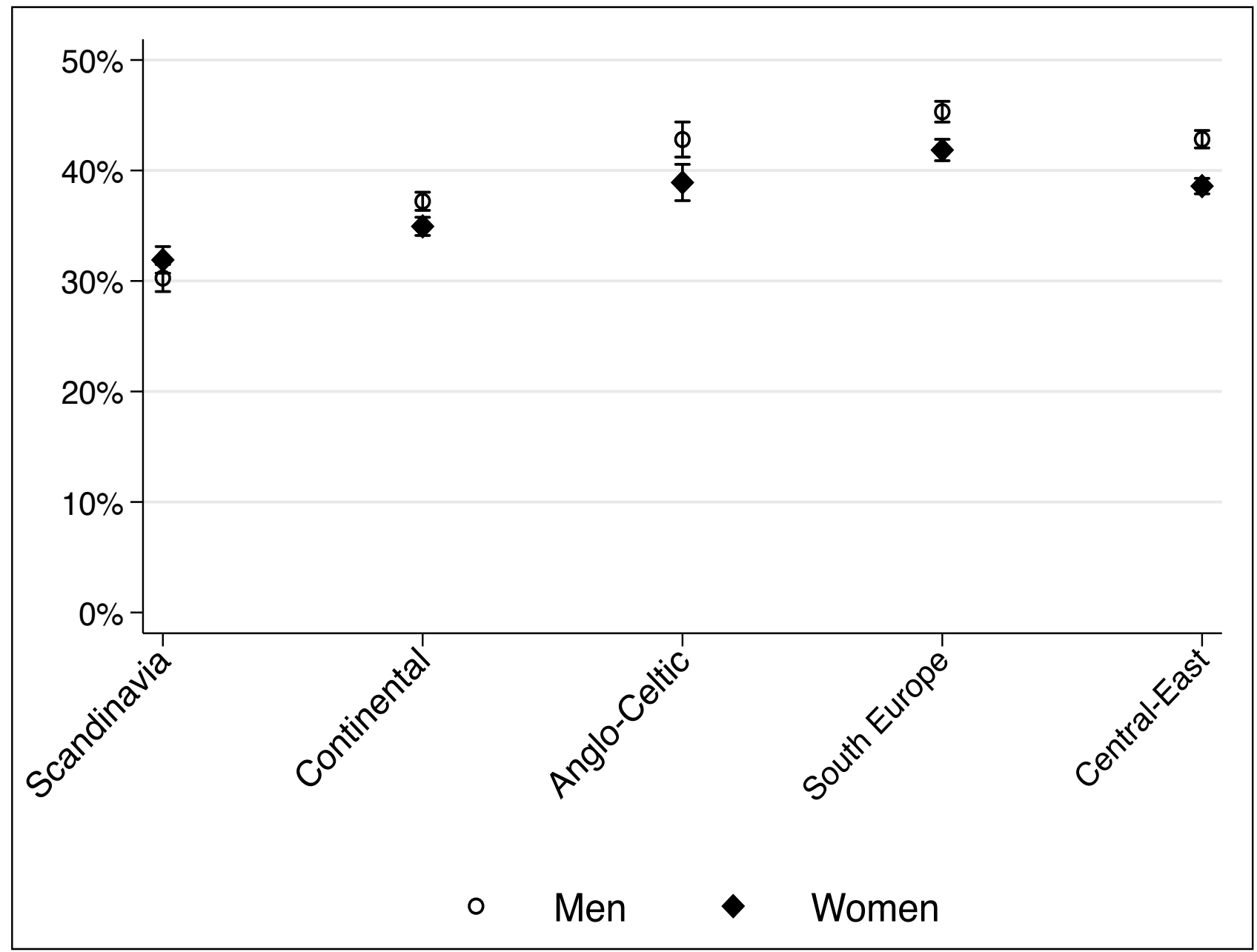

Note: Employees aged 18-64 for a pooled sample with Wave 1 (2005), Wave 2 (2010), and Wave $3(2015)(\mathrm{N}=93,879)$. The predicted probabilities (converted from a 0 to 1 scale to a 0 to 100 scale, to ease its interpretation) are based on logistic regression models, adjusting for age, year, education, occupational sector, family income, migrant status, parenthood status, and marital status. 